\title{
Probing impact of fast food on health and obesity of the youth aged II-I5 in Tehran city in 1993
}

\begin{abstract}
Background: Obesity is currently affecting people all over the global. The problem of overweight and obesity groups at risk, such as children and adolescents threatens our country too. The aim of this study was to probe one of the obesity risk factors such as fast food on the health of adolescents. The Increase in fast food consumption in recent years has left negative impacts on the youth. Accordingly, recognition of reason and the level of fast food consumption and its effects on the health of children and adolescents are more important.
\end{abstract}

Methods: This descriptive and analytical study was conducted among 471 general students (261 boys and 210 girls) aged 11-15. Also, multi-stage sampling was performed. The questionnaire included: Causes and the extent of use of fast food, physical activity, family situation and anthropometry factors that were measured by the nutritionist. The data collected was analyzed using SPPSS19 software.

Results: The result of this study illustrates the level and relevance of consumption of fast food to family literacy, economic situation, parent's occupation, branch eating frequency and paucity of nutritious food in family. The study revealed that $7.15 \%$ were in the vicinity of BMI obesity grate $1,29.3 \%$ were overweight, $6.48 \%$ normal and the rest were thin. Also the $2.28 \%$ of obesity and overweight students surveyed were boys. In this study, $3.36 \%$ of the adults declared that they had eaten fast food in the previous week. Weekly consumption of fast food was as follows: $29.4 \%$ sandwiches, $22.4 \%$ snack, $15.9 \%$ Hamburger, $14.8 \%$ pizza, $9.4 \%$ hotdog, $8.1 \%$ chicken nugget.

Conclusion: By comparing today's weight of the adolescents with the last year, we can conclude that students who ate fast food more than twice a week had a $74 \%$ chance of being subject to obesity. The finding; show that complications of fast food consumption are revealed in the youth and that non-epidemic diseases spread among the youth every day. Therefore it's necessary to probe other factors paving the way for obesity.

Keywords: fast food, healthy, obesity
Volume 3 Issue 2 - 2015

\author{
Hyacinth OU \\ Science \& Research University, Iran
}

Correspondence: Homa Dareini, Bachelor of Nutrition Sciences, Science \& Research University, Tehran, Iran, Email dareinihoma@yahoo.com

Received: June 01, 2015 | Published: October 13, 2015

\section{Introduction}

At the present time, non-contagious diseases are among important reasons of mortality in the world. This is while statistics issued by the World Health Organization show that $60 \%$ of mortality causes and $43 \%$ of diseases are due to non-contagious diseases. Moreover, this organization has anticipated that, spread of non-contagious diseases will reach $60 \%$ until 2020 .

These diseases include the following: Cancer, heart diseases, diabetes, heart attack, brain stroke and blood pressure that are caused directly by 3 factors:
a. Smoking
b. Lack of sport activity
c. Unhealthy nutrition.

Obesity is currently affecting people all over the globe. The problem of overweight and obesity threatens groups at risk in Iran such as children and adolescents. The aim of this study was to probe one of the obesity risk factors such as fast food on the health of adolescents. The Increase in fast food consumption in recent years has left negative impacts on the youth. Accordingly, it is important to recognize the reasons behind and the level of fast food consumption and its effects on the health of children and adolescents. ${ }^{2}$

Due to change in life style moving from traditional to industrial life we increasingly witness that lack of physical exercise and imbalance in receiving and consuming energy and also getting accustomed to computer games have led to obesity and overweight in children. Incorrect nutritional habits have replaced traditional, healthy food. On the other hand, media advertisements have led to a dramatic increase in consumption of fast food in the past 3 decades (Figure 1).

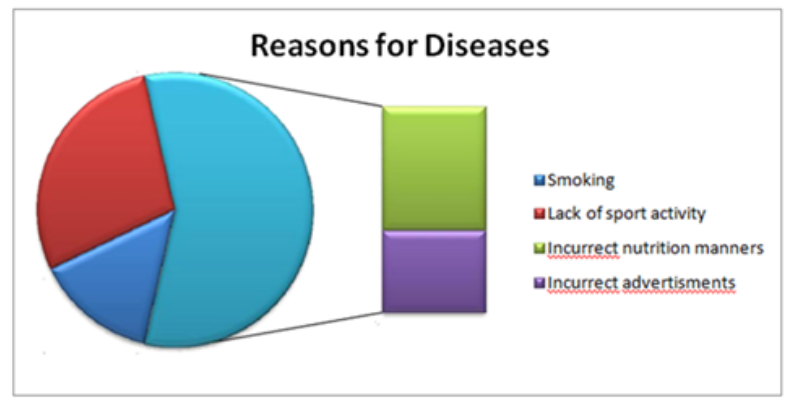

Figure I Reasons for diseases. 
Fast food blocks vessel because they contain trans-fat and increase the possibility of brain stroke, heart attack and atherosclerosis. Because of possessing high calories, high sodium, high fat, low minerals, lack of adequate vitamin and calcium, fast foods cause obesity among the youth. ${ }^{3,4}$

Obesity or overweight in this group is an important issue because it is likely that student's self-esteem will decline among their peers. It also causes psychological disorders. Wilmore and Kastin define obesity as a condition where the body has absorbed fat more than necessary. Men possessing more than $25 \%$ and women over $35 \%$ fat are considered obese. According to the result of studies carried out in the past, consumption of excessive fast food cause various diseases such as heart attacks, brain stroke, metabolic syndrome, allergy, asthma and diabetes. ${ }^{5}$

\section{Methods}

This descriptive and analytical study was conducted among 471 general students ( 261 boys and 210 girls) aged 11-15. Also, multi-stage sampling was performed. The questionnaire included: Causes and the extent of use of fast food (such as inadequate cooking by mother, trusting the healthiness and provocation by friends), physical activity, family situation, the kind of fast food consumed and anthropometry factors (weight, height, BMI). All the data collected were measured by the nutritionist. The data collected was analyzed using SPPSS19 software.

\section{Results}

The result of this study illustrates the level and relevance of consumption of fast food to:
i. Family literacy
ii. Economic situation o Parent's occupation
iii. Branch eating frequency
iv. Paucity of nutritious food in family

In this study, $32.9 \%$ of the adults declared that they had eaten fast food in the previous week. The study revealed that $31.85 \%$ were in the vicinity of BMI overweight, $3.82 \%$ were obesity grade 1 . This means that one third of those surveyed had a weight above the normal range. $54.35 \%$ were normal and the rest were thin. Also, $60.4 \%$ of obesity and overweight students surveyed were boys (Table 1).

Table I Weight

\begin{tabular}{|c|c|c|c|c|}
\hline & & Value & Count & Percent \\
\hline \multirow[t]{6}{*}{ Standard Attributes } & Position & I & & \\
\hline & Label & Weight level of adolescents & & \\
\hline & Type & Numeric & & \\
\hline & Format & F8.2 & & \\
\hline & Measurement & Nominal & & \\
\hline & Role & Input & & \\
\hline \multirow[t]{2}{*}{$\mathrm{N}$} & Valid & 471 & & \\
\hline & Missing & 471 & & \\
\hline \multirow[t]{6}{*}{ Central Tendency and Dispersion } & Mean & 2.3758 & & \\
\hline & Standard & 0.73584 & & \\
\hline & Deviation & & & \\
\hline & Percentile 25 & 2 & & \\
\hline & Percentile 50 & 2 & & \\
\hline & Percentile 75 & 3 & & \\
\hline \multirow[t]{4}{*}{ Labeled Values } & 1 & BMI: under I8.5 & 47 & $9.98 \%$ \\
\hline & 2 & BMI: I8.5- 24.9 & 225 & $54.35 \%$ \\
\hline & 3 & BMI: 25- 29.9 & 174 & $31.85 \%$ \\
\hline & 4 & $30-34.9$ & 25 & $3.82 \%$ \\
\hline
\end{tabular}

The kind of weekly fast foods consumed by the youth were probed. The findings of the investigation are as follows: $27.8 \%$ sandwiches, $23.5 \%$ snacks, $18.25 \%$ Hamburger, $14.22 \%$ pizza, $10.4 \%$ hotdogs, $5.7 \%$ chicken nugget (Figure 2).

Parent's education and occupation play important roles in family nutritional habits. My study shows that students who were obese or suffered from overweight had parents with low educational degree. In another word, the level of mother or father's education is important and it is relevant to children's growth and health.

In this study, $84 \%$ (395 persons) of mothers had educational degrees under BS or BA and only $16 \%$ (76 persons) of them had BS or BA and higher. Moreover, $68 \%$ (320 persons) of fathers had 
under BS or BA educational degree. We can say $32 \%$ (151 persons) of them had BS or BA. Actually, educated men were twice more than educated women. In general, I should insist that most of the students who suffered from overweight or obesity in the Tehran schools where I carried out this study had parents without high educational studies or university degrees (Figure 3).

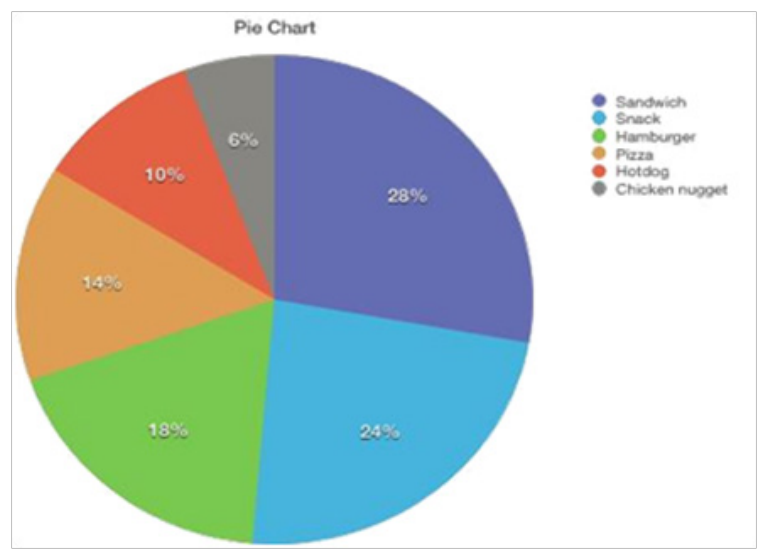

Figure 2 Weekly fast foods consumed by the youth.

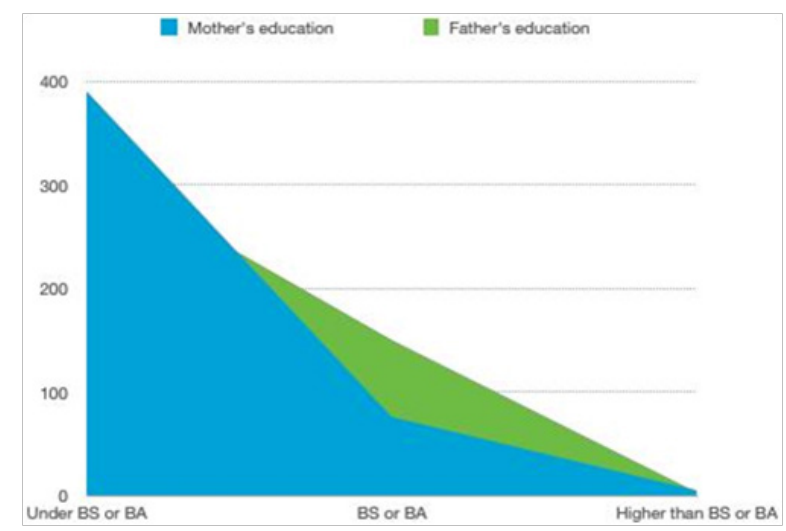

Figure 3 Parents without high educational studies or university degrees.

I investigated the influence of mothers both housewives and those employed on encouraging their children to consume fast foods. Surprisingly, I found out that most of children using fast food had housewife mothers (Figure 4). ${ }^{5}$

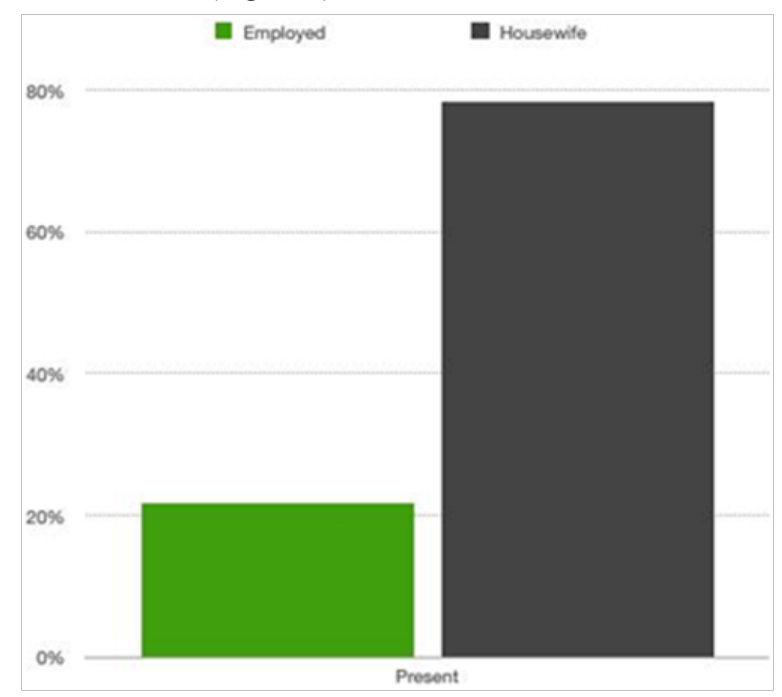

Figure 4 Most of children using fast food had housewife mothers.

\section{Conclusion}

By comparing the current weight of adolescents with last year, we can conclude that students who ate fast food more than twice a week had a $74 \%$ chance of being subject to obesity. The findings show that complications of fast food consumption are revealed in the youth and that non-epidemic diseases are increasingly spreading among the youth. Therefore, it's necessary to probe other factors paving the way for obesity.

My study shows that the youth prefer fast foods over foods cooked at home. This is because of the taste of fast foods compared to traditional foods, impact of students who encourage use of fast foods and finally easy access to fast foods for families in industrial cities like Tehran.

Therefore, there is a need to draw up plans to control consumption of fast foods and prevent such advertisements in the media. Among other measures needed for improving public health is to encourage citizens to engage in physical activities.

\section{Acknowledgements}

None.

\section{Conflict of interest}

The author declares no conflict of interest.

\section{References}

1. Kathleen Mahan L, Janice L Raymond, Sylvia Escott-Stomp. Krause's food and the nutrition care process. 13th ed. Elsevier; 2012. $1248 \mathrm{p}$.

2. Elizabeth Poskitt, Laurel Edmunds. Management of childhood obesity. UK: Cambridge University Press; 2008. 232 p.

3. Larry Kenney W, Jack Wilmore, David Costill. Physiology of sport and exercise. 6th ed. Human Kinetics; 2015. 648 p.

4. Kendra Kattelmann K. Childhood obesity prevention: International research, controversies and interventions. $J$ nutrition Education and behavior. 2012;44(2):194.

5. Hall, Guyton. Textbook of medical and physiology. 12th ed. 2010.1112 p. 